\title{
3
}

\section{Three Dimensions of Purpose: Knowledge, Motivation, and Action}

\author{
Carlos Rey and Miquel Bastons
}

\begin{abstract}
During a strategy class on the subject of purpose, a student approached the professor and said: "Look at this article, it says that in this company people dance at meetings and in their office they have pool tables, foosball, X-Box ... the whole company is decorated as if it were a beach in the Caribbean, because it is the place where all the employees affirmed that they would like to work. "The professor was intrigued by this company and decided to invite its CEO to his classroom. The $C E O$ agreed and shared with the students how he was trying to create a great culture within his organization. He told them about the importance of having a purpose, of the sense of work, of inner balance, of being comfortable with oneself. He told them about the games in the office, the Caribbean decor, and dancing at meetings. Once his presentation was over, a student asked: Could you explain to us your business? The man explained that he had 70 stores, 300 employees, a warehouse, and he was in the process of giving more details, but then came a second question: one of the students asked what is the reason for the dancing, does it somehow contribute to the business? He replied: no, we don't really do this for the business. Then came a third question, about the 70 stores: Do the 300 workers there also dance and have foosball, PlayStation, and pool tables? Well, no, they don't. The stores have to take care
\end{abstract}

\section{Rey $(\bowtie)$}

Universitat Internacional de Catalunya, Barcelona, Spain

e-mail: carlosrey@uic.es

M. Bastons

Department of Economy and Business Organization, Universitat Internacional de Catalunya, Barcelona, Spain

e-mail: bastons@uic.es 
of our customers. And finally came the most important question; in a respectful but incisive tone a student asked: what do you tell your store employees when they read in the press that their colleagues in headquarters are dancing and playing pool and $X$-Box? Just then, the teacher looked at the time and said: well, the class is over! After two weeks, the professor distributed a survey to this company's employees, in order to assess how they internalized the organization's purpose. Did they understand and share in the purpose? Interestingly, their results were among the worst in a broader study of 200 companies.

The following year the teacher ran across a good friend who told him: I know a CEO whom you should meet, he has recently remodeled the entire office. It now includes pool tables, foosball, and yoga spaces... they even gave it a name ... they call it the "optimist building." As a precaution, before inviting the CEO, the professor distributed the same survey on purpose internalization. The results were impressive: This company ranked as one of the highest in the survey of all 200 companies. The following Friday, the CEO arrived to class.

He showed a single slide. It read: "The Purpose of the Organization" and under it were listed many concepts that, at first glance, might seem to be a disconnected hodgepodge of lofty ideals and hard-headed results. Things like: market share, the sense of work, productivity, love for customers, return on investment, happiness of the workers, social concern, cost control, purpose, strategy, optimism, efficiency. He greeted the students and said: "I'm going to talk about the purpose of my company," and for an hour and a half he explained how he connected "everything" to "everything." As he talked, it was hard not to notice his deep authenticity, coherence, and integrity in everything he discussed about the business. This was one of the best lessons about purpose they had ever received.

In recent years, we have seen an increasing interest in academic research about purpose both in individuals ${ }^{1}$ and in organizations. ${ }^{2}$ Benefits of purpose have been found, for example, in areas as diverse as health, well-being, work productivity, learning, innovation, and financial performance. ${ }^{3}$ In pursuit of these and other benefits, companies invest time and effort in devising an elaborate and well-crafted corporate purpose that articulates, for the public, their core values and main goals. However, the most challenging task is to create a purpose that really touches the hearts and minds of the employees, makes them feel proud of being part of the company, and leads to shared ambitions. ${ }^{4}$ Contemporary organizations need to create an effective purpose that is successful in eliciting the emotional commitment of the employees. This process is not about designing a statement that will be printed on organizational documents, but rather one that will be imprinted in the heads-and especially the hearts_of employees. Defining and communicating such an effective purpose is not an easy task. 
Table 3.1 Examples of 'linear' frameworks for purpose development

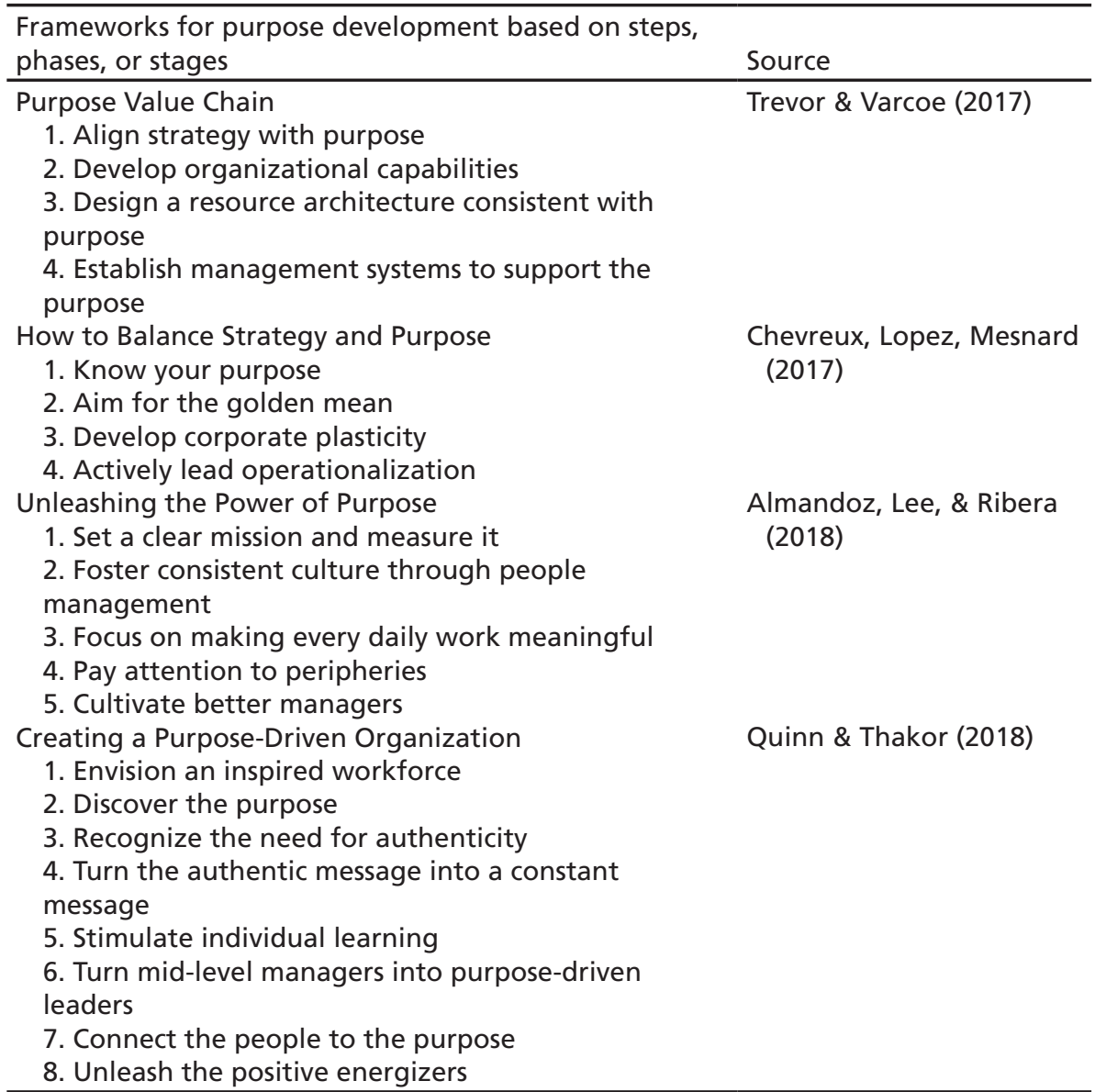

Trevor, J., \& Varcoe, B. (2017). How aligned is your organization? Harvard Business Review Digital Articles, pp. 2-6; Chevreux, L., Lopez, J., \& Mesnard, X. (2017). The best companies know how to balance strategy and purpose. Harvard Business Review Digital Articles; Almandoz, J., Lee, Y., \& Ribera, A. (2018). Unleashing the power of purpose: 5 steps to transform your business, IESE Insight, 37, Second Quarter, 44-51; Quinn, R. E., \& Thakor, A. V. (2018, July-August). Creating a purpose-driven organization. Harvard Business Review, pp. 78-85.

It is no surprise that a plethora of new books and articles have recently appeared to help guide companies on their way to becoming purpose-driven organizations. From the theoretical and practitioner side, there are new frameworks developing as a result of the analysis being done on successful purpose-driven companies like McDonald's, Walt Disney, Apple, and others (see Table 3.1).

These frameworks, elaborated by academics and consultants, analyze purpose under the lens of linear logic using steps, phases, or sequential stages. 
Not by coincidence, this nicely resembles the classical three-step strategic planning framework of analyze, design, and execute, built, as well, on linear logic. To a certain extent, there is wisdom in this perspective, as academics and consultants need to sell their ideas, which usually are easier to convey when they are explained through linear reasoning. Such frameworks certainly capture learning from the field and highlight important tips for developing purpose-driven organizations.

However, the linear approach has relevant limitations. It can lead to the misleading belief that successful cases of purpose-driven organizations like Apple or Walt Disney are the consequence of a linear movement that goes from "A" to "B." But purpose is not of that nature. From recent research on purpose, we know that the linear approach can significantly harm purpose development, especially its effective internalization and consistency. This is due to the fact that the development of purpose commonly requires balancing multiple objectives (e.g. prosocial and economic goals), ${ }^{5}$ that are not entirely compatible with one another, "which makes a simple linear approach very hard to sustain." 6 Purpose development requires an "oblique" approach that provides causal explanations between concepts that apparently may be considered disconnected. ${ }^{7}$ An example of oblique logic is "purpose first, profits second." Instead of indicating a linear relationship, it establishes an indirect relationship. Another example could be: "first give, then receive," on which many companies have built their purpose (e.g. Mercadona ${ }^{8}$ ), or the one of DaVita": "community first, company second." Here, purpose development is primarily based on an oblique logic, especially relevant when the different objectives of the company are not entirely compatible. It is consistent with what some call "to put things in proper order": when purpose is achieved, monetary benefits can be its natural outcome. ${ }^{10}$ As Ratan Tata, former CEO of the Tata Group, has observed, "you can make money by doing good things rather than the other way around." 11

We invite you to make a simple experiment. Go to any company you know with a really embedded purpose, where it emerged naturally. When you speak with the people, they will rarely tell you things like: "We first defined the purpose, second we enculturated it and then we articulated it." Instead, they will describe stories, living tales, and anecdotes, all full of oblique logic. In the personal sphere, you can do a similar exercise when encountering people who naturally live their personal purpose in life (or simply think about how you do it yourself). More than linear frameworks, you will discover a lot of oblique reasoning. "Put family and friends first and good things will come," is an example obtained from the CEO of a successful high-tech company when asked how he maintains his purpose in life. 


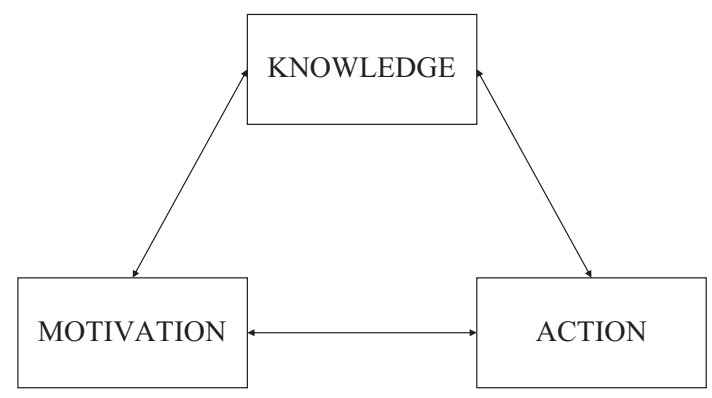

Fig. 3.1 3D model of purpose (Based on Rey, C., \& Bastons, M. (2018). Three dimensions of effective mission implementation. Long Range Planning, 51, 580-585)

The conceptual and practical understanding of purpose development should not be formed in linear reasoning. But rather, think of it as more related to what some call "practical wisdom," that "synthesizes "knowing why' with 'knowing how' with 'knowing what'." 12 So, frameworks based on linear logic alone do not lead to effective implementation of purpose, because the nature of purpose is not linear. The nature of purpose is formed by three unique yet interrelated components: knowledge, action, and motivation (see Fig. 3.1). The first dimension, knowledge, represents the explicit understanding members have about an organization's purpose. The second, action, reflects the practical fulfillment of purpose. And finally, motivation, the most intimate side of the purpose, is represented by the deep needs found in every one of us.

\section{Purpose as Knowledge}

For purpose to develop, individuals need to know it, and be able to express it in their own words. In this regard, purpose is related to what is commonly called "the purpose statement." That is, for example, the definition of purpose by Bartlett and Ghoshal as "the statement of a company's moral response to its broadly defined responsibilities." 13 From this perspective, purpose can be viewed as a formal commitment, one which embraces social needs and problems, and not as some platitude regarding social responsibility or an abstract idea pointed at satisfying specific stakeholder needs. It is understood as the reason for the being of the business itself.

Many researchers have recognized the importance of having explicit knowledge around purpose. For example, when relating purpose to profits, scholars distinguished between "purpose camaraderie" and "purpose clarity," where 
only the second is associated with better results. ${ }^{14}$ And having clarity of purpose helps both organizations and individuals alike, especially in times of uncertainty and turbulence, when individual decisions and actions are more easily blown off course. Purpose cannot be taken for granted. It has to be at the forefront of consciousness. Its presence can transform a firm, but its loss can destroy an institution. ${ }^{15}$

It is important to recognize that organizational purpose can be greatly influenced by the living principles of the founder, like Starbucks: "to inspire and nurture the human spirit" is an extension of Howard Schultz's beliefs. But for many, purpose is the result of a true north developed and formed over time. There is a certain paradox to this: purpose is formed over time and through changing circumstances, and yet, once clarified, it does not change with time or circumstances. This is why, when organizations reflect on purpose, they must look toward its essence and the fundamental meaning that has always been present, and has endured the test of time. Questions like-what does your company stand for? What was the original founding philosophy? How would society be worse off or different without your company? - can be a good way to start discovering the purpose. ${ }^{16}$

\section{Purpose as Action}

The idea that purpose encompasses action is relatively intuitive. An organization can reinforce its purpose once it is written, but the significance of purpose is not limited by the boundaries of the purpose statement. Similar to the way in which the knowledge of purpose is made explicit through statements, purpose as action is made explicit through its operational development. Consider, for example, the internet eyewear retailer Warby Parker, where the company's purpose- "to do good"-is extended in actions like ensuring for every pair of glasses sold, a pair is distributed to someone in need. ${ }^{17}$

Indeed, this second understanding of purpose-as action-provides a different approach to the concept of purpose. We could say that, with regard to knowledge, the nature of purpose is formal and static-focused on the statement and its content. While with regard to action, the purpose becomes dynamic. What matters in the latter, is not just the content of the statement but the degree or extent to which the company is putting into practice what it says in its purpose statement. And in this way, purpose becomes something related not only to some specific actions, but to 
the whole activity of the company. Thus, purpose must be applied to all the arenas in which the company performs its activities and makes its decisions.

The relevance of purpose as action and its influence on meaning can be seen in recent findings that invite us to consider how leaders inspire employees not only through the words they use to link work to purpose, but also through their actions that redesign work. ${ }^{18}$ This approach is in line with several authors' proposals to evaluate the performance relative to purpose and to express purpose in terms of specific results. ${ }^{19}$ Indeed, the purpose statement is merely an intellectual exercise, but you need the systems and procedures to bring it to life. It is related to how the companies measure their success beyond the mere economic or financial results. This is for example the case of DaVita; following the principle of "we say, we did," the company measures every outcome it can to assess how well their purpose is becoming a reality. ${ }^{20}$

Using measures and indicators to evaluate purpose requires one to accept the tension between saying on the one hand "you cannot manage what you don't measure" and on the other, "there are important things that you cannot measure but you need to manage." Purpose measurement requires using metrics to evaluate its fulfillment but also understanding that the legitimacy of measurement is always sustained by the purpose itself. And when measurement becomes the end in itself, it detracts from the sense of purpose. This was nicely labeled by a manager of one company as "Indicator-itis." After some years of measuring their purpose according to a set of indicators, he observed that some of his managers were confusing indicators with the purpose itself. Another example of "Indicator-itis" can be seen in the findings of Insead Professor Quy Huy in his analysis of the fall of Nokia. Rather than focusing on the purpose, "top managers were afraid of the external environment and not meeting their quarterly targets." ${ }^{21}$ Purpose metrics must be dynamic, helping to express the purpose based on both the external realities of markets and the internal conditions of the organization.

\section{Purpose as Motivation}

Knowledge and action reflect two basic interrelated dimensions of purpose. However, to understand the true essence of purpose we need to consider a third dimension, one that draws on the beliefs and motivations of the individual. ${ }^{22}$ Consider, for example, the case of an area director at ISS Facility services, a European company with more than 3000 employees. Every year 
this director gathers his team for a one-day meeting in which they discuss their strategy, results, objectives, and action plans. In the last meeting, however, he opened with a proposal that surprised everyone: "this year we are not going to dedicate the day to reviewing how we fulfill our purpose, rather we are going to devote the whole day to reflect on how we feel the purpose in our lives."

When purpose touches the heart of a person, it becomes a great source of energy that helps one to transcend their own interest, further fueling the fulfillment of purpose. ${ }^{23}$ Considering purpose solely from the perspective of a statement or the purposeful action simplifies the concept of purpose. In practice, a purpose such as "improve people's lives" certainly carries the implicit purpose "to ensure that employees are personally motivated to improve people's lives." Although, improving people's lives, this is not their true purpose if the only motivation of the organization is to make money. As stated by IESE Business School professors, "If the only motivation of purpose is because it might make you more money, then you really need to ask yourself whether your motivation is right in the first place." ${ }^{24}$ Purpose boost profits only if it is pursued for its own sake. ${ }^{25}$ Indeed, in our experience, this is the root cause of most of the failures we have seen: the "purpose of the purpose" was not the purpose.

\section{Internalization, Implementation, and Integration}

The way genuine purpose is nurtured in organizations nicely resembles a spiral, turning around a fixed point or center. When companies are true to their purpose, the three dimensions of purpose approach each other and knowledge, motivation, and action become unified. This is the main difference between the linear approach of purpose and the oblique approach that we will describe and build throughout this book. It is not simply about doing things to develop purpose, no, it is placing purpose as the central point around which all else turns. That means developing the three dimensions of purpose in a concurrent and harmonious fashion. If we develop only one or two without the other(s), the purpose suffers.

We have seen many examples of this in the marketplace. Take Aigües de Barcelona, a water supply company. Inspired by their purpose: "committed to people, we care for our water and build the city" the management team launched a program with 20 purpose-driven projects deployed throughout 
the organization. However, after one year the results were disappointing. It was not until they started fostering internalization of the purpose in middle managers and employees that they saw these projects providing greatly improved results. From this experience, they realized that, as one manager declared, "for purpose to be a reality, the purpose must be loved." This and many other experiences show that it is necessary to place an intermediate element between knowledge and practice: purpose must be loved and internalized by organizational members. Therefore, purpose development needs a three-dimensional approach, integrating simultaneously knowledge with motivation (internalization), knowledge with action (implementation), and motivation with action (integration) (Fig. 3.2).

Purpose internalization is the connection between the knowledge of purpose and the motivation. It is the process through which organizational members "buy into" the purpose of the company, incorporating it in their beliefs and motivations. No doubt, the first to benefit from internalization is the company itself, as it is the basis on which unity is built. Purpose internalization is what turns purpose-such as "promote well-being in society" - from an abstraction into something truly sought after by its members. Without this, we could say that purpose does not exist. In other words, to understand the "why" of an organization, we must consider the "why" of each member within the organization, as well as their underlying motivations.

The internalization of purpose creates this link by reflecting a person's motivations relative to the fulfillment of purpose. It is the development of these motivations that go beyond economic incentives (extrinsic motivations) and self-satisfaction (intrinsic motivations). They aim at meeting the needs of

2D LINEAR APPROACH

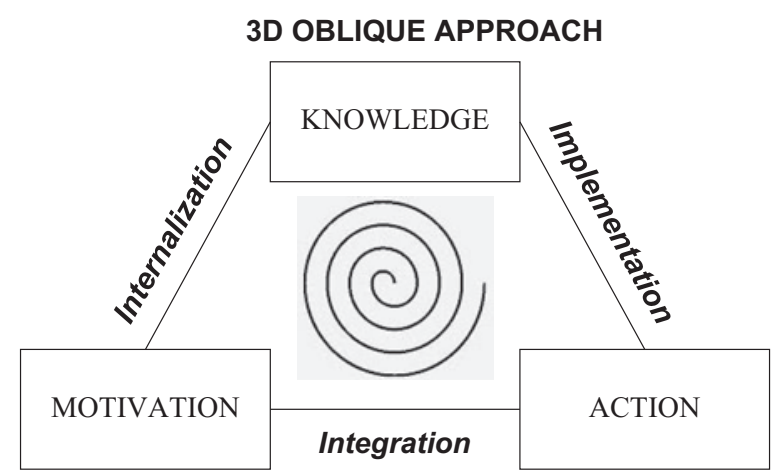

Fig. 3.2 Linear and oblique approach for purpose development 
others and, therefore, depend on "pro-others motivation," identified in the research as "prosocial motivation." ${ }^{26}$ Naturally, purpose internalization should be sought among employees in the first place, but it may also be found in other agents who act as "contributing agents" to the fulfillment of purpose. An example of this can be found in the efforts companies make to incorporate their customers, suppliers, and shareholders into their purpose. Think about, for example, the case of Aigües de Barcelona. They take significant effort in making their customers (the citizens) conscious of the sustainable use of water, motivating them to use better water management practices.

Purpose implementation is the connection between the knowledge of purpose and the action. When a company effectively implements purpose, it can be seen in the contributions it makes to society and to the people around it. Purpose implementation has two basic expressions. The first looks back in time to the degree in which a company's practices correspond to its purpose, ultimately looking to answer the question "how are we fulfilling our purpose?" The second looks toward the future and involves expressing the purpose in terms of events and results that must be achieved going forward. In this regard, expressing purpose in concrete actions and results becomes part of the purpose implementation itself. What matters then is the extent to which the company fulfills and intends to fulfill its formal purpose-what the company has done and intends to do. The importance of purpose, then, translates to a practical realm by guiding the company in aspects such as defining strategy, communicating objectives, or making tactical choices. Implementing purpose through the challenges and activities we deal with daily ultimately helps enhance the meaning of work. Purpose implementation provides clarity and confidence, helping employees to stay the course and remaining true to the essence of the organization. Implementation and internalization must always go hand in hand, developed in a simultaneous fashion. Advances in purpose implementation without internalization risk failing over time, being perceived as inauthentic strategy development, or simply incoherent with regard to the organization's professed purpose.

Purpose integration is the natural connection between the motivation and the action. This integration is the result of combining implementation and internalization in a natural way. It is about transforming purpose into a "habit" that is performed on a regular basis in harmony with the individuals' motivations. It is earned over time and stimulates the ability to transform purpose into everyday action. In some way, integration is the quality of placing purpose in everything we do, both in the most significant and in the most commonplace. Purpose integration is what differentiates for example, a sales person that makes a sale simply to cover the budget, from the sales person that 
makes a sale for the betterment of a client. Purpose integration reflects the purity of intention in our daily tasks and objectives, and helps build trustworthy and lasting relationships between the company and its stakeholders. Likewise, we see a lack of integration when companies talk in platitudes and altruisms (like we see with too many CSR programs), but fail to integrate purpose into their daily practices or when they make unnecessary use of economic incentives for activities that already carry a prosocial motivation.

These three processes - internalization, implementation, and integrationdo not form a linear model. They are not sequential steps, phases, or stages, nor is there a direct cause-effect relationship between them. But rather, these three processes are tied by an oblique (or indirect) relationship: one cannot be properly developed without the others, and they must be developed simultaneously, when trying to apply them in the daily life of the organization. The spiral depicted by the incremental and simultaneous development of the three processes makes the difference between simply implementing a "purpose plan" and consistently striving to be true to your company's purpose over time. It shows how purpose-driven companies connect "everything to everything," because they connect everything to purpose.

\section{Notes}

1. Grant, G. B. (2017). Exploring the possibility of peak individualism, humanity's existential crisis, and an emerging age of purpose. Frontiers in Psychology, $8,1478$.

2. Hollensbe, E., Wookey, C., Hickey, L., George, G., \& Nichols, C. V. (2014). Organizations with purpose. Academy of Management Journal, 57(5), $1227-1234$.

3. For a review of purpose benefits see: Yemiscigil, A. (2018). Purpose: A new paradigm with implications for policy, business, and individual lives. Unpublished manuscript, Istanbul: Global Relations Forum.

4. Carton, A. M., Murphy, C., \& Clark, J. R. (2014). A (blurry) vision of the future: How leader rhetoric about ultimate goals influences performance. Academy of Management Journal, 57(6), 1544-1570.

5. Porter, M. E., \& Kramer, M. R. (2006). The link between competitive advantage and corporate social responsibility. Harvard Business Review, 84(12), 78-92.

6. Birkinshaw, J., Foss, N. J., \& Lindenberg, S. (2014). Combining purpose with profits. MIT Sloan Management Review, 55(3), 49-56.

7. Foss, N. J., \& Lindenberg, S. (2013). Microfoundations for strategy: A goalframing perspective on the drivers of value creation. Academy of Management Perspectives, 27(2), 85-102. 
8. Leading distribution company in Spain.

9. American healthcare company.

10. Almandoz, J., Lee, Y., \& Ribera, A. (2018). Unleashing the power of purpose: 5 steps to transform your business, IESE Insight, 37, Second Quarter, 44-51.

11. Birkinshaw, J., Foss, N. J., \& Lindenberg, S. (2014). Combining purpose with profits. MIT Sloan Management Review, 55(3), 49-56.

12. Nonaka, I., Chia, R., Holt, R., \& Peltokorpi, V. (2014). Wisdom, management and organization. Management Learning, 45(4), 365-376.

13. Bartlett, C. A., \& Ghoshal, S. (1993). Beyond the M-form: Toward a managerial theory of the firm. Strategic Management Journal, 14(S2), 23-46.

14. Gartenberg, C., Prat, A., \& Serafeim, G. (2019). Corporate purpose and financial performance. Organization Science.

15. Mourkogiannis, N. (2014). Purpose: The starting point of great companies. New York: St. Martin's Press.

16. Arena, C. (2007). The high purpose company. Jakarta: Gramedia Pustaka Utama.

17. Gulati, R. (2018). Structure that's not stifling. Harvard Business Review, 96(3), 68-79.

18. Grant, A. M. (2012). Leading with meaning: Beneficiary contact, prosocial impact, and the performance effects of transformational leadership. Academy of Management Journal, 55(2), 458-476.

19. Rey, C., \& Bastons, M. (2018). Three dimensions of effective mission implementation. Long Range Planning, 51(4), 580-585.

20. Almandoz, J., Lee, Y., \& Ribera, A. (2018). Unleashing the power of purpose: 5 steps to transform your business, IESE Insight, 37, Second Quarter, 44-51.

21. Huy, Q., \& Vuori, T. (2015, September 22). Who killed Nokia? Nokia did. INSEAD Knowledge.

22. Rey, C., \& Bastons, M. (2018). Three dimensions of effective mission implementation. Long Range Planning, 51(4), 580-585.

23. Campbell, A., \& Nash, L. L. (1992). A sense of mission: Defining direction for the large corporation. Reading, MA: Addison-Wesley Longman.

24. Almandoz, J., Lee, Y., \& Ribera, A. (2018). Unleashing the power of purpose: 5 steps to transform your business, IESE Insight, 37, Second Quarter, 44-51.

25. Mourkogiannis, N. (2014). Purpose: The starting point of great companies. New York: St. Martin's Press.

26. Grant, A. M. (2007). Relational job design and the motivation to make a prosocial difference. Academy of Management Review, 32(2), 393-417. 
Open Access This chapter is licensed under the terms of the Creative Commons Attribution 4.0 International License (http://creativecommons.org/licenses/by/4.0/), which permits use, sharing, adaptation, distribution and reproduction in any medium or format, as long as you give appropriate credit to the original author(s) and the source, provide a link to the Creative Commons licence and indicate if changes were made.

The images or other third party material in this chapter are included in the chapter's Creative Commons licence, unless indicated otherwise in a credit line to the material. If material is not included in the chapter's Creative Commons licence and your intended use is not permitted by statutory regulation or exceeds the permitted use, you will need to obtain permission directly from the copyright holder. 